\title{
Catrumanos:
}

\section{A representação do outro como ameaça em Grande sertão: veredas}

\author{
Ana Daniela Neves ${ }^{1}$
}

RESUMO: Neste artigo, a representação do outro como ameaça em Grande sertão: veredas, mais especificamente dos catrumanos, é explorada primeiramente confrontando leituras de críticos literários brasileiros importantes que escreveram a seu respeito. Depois, tenta-se estabelecer conexões entre os problemas equacionados nos trabalhos de Lukács, Jauss e, especialmente, no de Hermenegildo Bastos, todos relacionados à questão da ameaça natural.

PALAVRAS-CHAVE: Grande sertão: veredas; representação; ameaça.

ABSTRACT: In this article, the representation of the other as a menace in Grande Sertão: veredas, specifically the backwoodsmen, is explored by comparing works of important brazilian literary critics who have written about it. Then this study aims to establish connections between the problems equated in the work of Lukács, Jauss, and especially Hermenegildo Bastos, all of them related to the issue of natural menace.

KEYWORDS: Grande sertão: veredas; representation; menace.

Primeiramente, cabe esclarecer que o objetivo deste artigo é antes colocar/repensar questões do que refutar ou propor respostas fechadas. Assim, o trabalho dos críticos brasileiros é retomado, de forma breve, com o intuito de perceber de que modo essas personagens tem sido interpretadas ao longo da história literária brasileira recente, que deu visão mais política, em sentido amplo, ao romance de Guimarães Rosa. Em seguida, abordaremos os trabalhos dos teóricos que trabalharam a questão da beleza natural e seu poder ameaçador, bem como a mudança de orientação

\footnotetext{
1 Integrante do Grupo de Pesquisa "Literatura e Modernidade Periférica" (CNPq), Mestranda da Universidade de Brasília (UnB), pesquisa a representação do outro em Grande sertão: veredas. Contato: anadaniela.neves@gmail.com
} 
estética depois de 1789, isto é, respectivamente, Lukács e Jauss, tentando estabelecer as conexões necessárias com o contexto brasileiro, tendo em consideração que esse "filtro" foi efetivado pelo crítico brasileiro Hermenegildo Bastos, em trabalho ainda não publicado. Por fim, após esses dois momentos, apresentamos uma tentativa de compreender a representação do outro em Grande sertão: veredas tendo como guia as discussões anteriores e a perspectiva da ameaça, relacionando-a mais detidamente à economia da obra.

A fim de contextualizar o enredo e de que entendamos a divisão dos tópicos e a abordagem realizada, ressaltaremos alguns aspectos importantes da estrutura de Grande sertão: veredas (1956). Esta obra é narrada sob o ponto de vista de Riobaldo, um exjagunço, semi-letrado, que depois de transcorrida a história, da qual é narradorprotagonista, a conta, em sua fazenda, para um interlocutor urbano e letrado, por meio de um monólogo ininterrupto. Trata-se de uma história de jagunços que guerreiam pelo sertão do norte de Minas e sul da Bahia. A maior parte da narrativa está relacionada à busca dos Judas, que mataram à traição Joca Ramiro, pai de Diadorim. Assim, é por meio do foco narrativo em primeira pessoa que vamos conhecer as outras personagens; é por meio da presentificação do passado que vamos conhecer a vida do protagonista. Feito isso, passemos às análises dos críticos literários brasileiros sobre as personagens focadas neste trabalho.

\section{Catrumanos $^{2}:$ qual o sentido de sua ameaça? ${ }^{3}$}

"Não consegui sentido no que eles ameaçavam, e vi que estavam aperrando as armas." (Fala de Riobaldo)

\footnotetext{
${ }^{2}$ Segundo o Dicionário Eletrônico Houaiss da Língua Portuguesa, catrumano, no regionalismo mineiro, é o mesmo que caipira, roceiro.

${ }^{3}$ Como foi dito anteriormente, o estudo da arte como forma de ameaça, retomando os estudos de Georg Lukács e Hans Robert Jauss, procurando filtrá-los à realidade brasileira e à questão do trabalho, é iniciativa do Professor Hermenegildo Bastos (UnB), formalizada no estudo dos poemas de Manuel Bandeira a ser publicado.

${ }^{4}$ ROSA, João Guimarães. Grande sertão: veredas. São Paulo: Nova Fronteira, 2006, p. 383.
} 
Antes de qualquer tentativa de resposta, vejamos o fragmento que narra o encontro de Riobaldo com os catrumanos pela primeira vez, quando ainda não era chefe, mas jagunço de Zé Bebelo. Depois, vejamos dois dos mais importantes críticos que escreveram sobre essas personagens do Pubo, procurando calcar a interpretação na relação entre literatura e sociedade - Walnice Galvão (1972) e Willi Bolle (2004).

E de repente aqueles homens podiam ser montão, montoeira, aos milhares mis e centos milhentos, vinham se desentocando e formando, do brenhal, enchiam os caminhos todos, tomavam conta das cidades. Como é que iam saber ter poder de serem bons, com regra e conformidade, mesmo que quisessem ser? Nem achavam capacidade disso.

Haviam de querer usufruir depressa de todas as coisas boas que vissem, haviam de uivar e desatinar. Ah, e bebiam, seguro que bebiam as cachaças inteirinhas da Januária. E pegavam as mulheres, e puxavam para as ruas, com pouco nem se tinha mais ruas, nem roupinhas de meninos, nem casas. Era preciso de mandar tocar depressa os sinos das igrejas, urgência implorando de Deus o socorro. E adiantava? Onde é que os moradores iam achar grotas e fundões para se esconderem - Deus me diga? (ROSA, 2006, p. 389-390).

Baseada no fragmento anterior, Walnice Nogueira Galvão afirma:

[Riobaldo] intui que a miséria excessiva está aquém de qualquer possibilidade de convivência, de qualquer padrão moral, de qualquer romantização: ela é feia, suja e perigosa. Sente a ânsia do miserável pela posse, pelo gozo imediato, mesmo ao preço da destruição total. (GALVÃO, 1972, p. 67).

Diz também que o quadro fantasmagórico e tremendo mostra a "plebe rural desencadeada, monstro coletivo que avança para tomar tudo o que foi negado por século de miséria e opressão". (GALVÃO, 1972, p. 67).

A partir dessas duas afirmativas pode-se perceber que Riobaldo não é visto como alguém que também pretende dominar, mas apenas compreender. Entretanto, o medo de Riobaldo advém tanto da consciência de não pertencer àquela classe, em primeiro lugar, quanto da necessidade de dominação, quando já é chefe e precisa de homens para o combate: 
Há-de, que se eles tivessem me pegado sozinho, eu apeado e precisado, decerto me matavam, para roubar minhas armas, as coisas e minhas roupas. Amargo que acabavam comigo, sem escrúpulos, hom'essa, que nem tinham, porquanto eu era desconhecido e forasteiro. (ROSA, 2006, p. 389).

Sob outro enfoque, Willi Bolle (apesar de não tratar dos catrumanos especificamente, mas do povo e dos pobres em geral) afirma que nas mais de 1.300 falas diretas dos jagunços têm-se a representação do povo, em que este é dono das palavras.

Entretanto, se relembrarmos o que Antonio Candido, em sua conferência "A literatura e a formação do homem" (1972), expõe sobre o problema do narrador culto x personagem inculto - problema constitutivo de nossa literatura, principalmente regionalista - veremos que o fato de haver 1.300 falas diretas dos jagunços em Grande sertão: veredas não é tão significativo. Expliquemos: Candido diz que a princípio nosso regionalismo era humanista apenas na temática, ao incorporar o excluído, pois a dose de reificação ficava assegurada pela diferença de representação entre o narrador e a personagem. Exemplo típico dessa dicotomia é a literatura de Coelho Neto, que utilizava a convenção fonética para retratar a fala da personagem em discursos diretos e a convenção da norma culta para os discursos indiretos, do narrador. Por outro lado, exemplo mais próximo do que Guimarães Rosa fez no nível narrativo foi Simões Lopes Neto, escritor regionalista do Sul, que adaptou a convenção da norma culta para representar.

Outro avanço realizado por esse escritor é a dissolução do homem culto em homem rústico. Dessa maneira, o narrador não é um intelectual distante de seus representados. Esse tipo de solução narrativa traz ao leitor não mais a personagem pitoresca, mas a personagem humana próxima ao próprio leitor urbano.

A partir dessa tradição literária da representação do outro na literatura brasileira, vemos que o central nessa questão não é o fato de se ter discurso direto de forma 
massiva em uma narrativa, mas o grande problema é saber como está transfigurada a relação dialética entre narrador e personagem.

\section{Dominação da natureza/Dominação do homem pelo homem}

Neste segundo momento, a partir dos estudos de Lukács (1967) e Jauss (1994), inicia-se uma tentativa de estabelecer conexões entre os problemas discutidos nesses trabalhos com a problemática da representação do outro em Grande sertão: veredas (especificamente, dos catrumanos). Essa conexão foi mediada por outro trabalho, o de Hermenegildo Bastos, que, além de pensar nesses problemas em termos de Brasil, acrescentou ao debate a dominação do homem pelo homem.

Jauss constata que depois de 1789, principalmente no século XIX, houve uma mudança de orientação estética. A natureza, antes percebida como um reduto, representando algo acolhedor e calmo, passa a ser vista como ameaçadora, amedrontadora, espaço hostil. Essa mudança de perspectiva está ligada à mudança de relação entre o homem e a natureza. O homem cada vez mais se distancia e se diferencia do natural, dominando-o de acordo com seus propósitos de progresso, de crescente industrialização e urbanização.

No caso das personagens em análise, representantes de uma ligação forte e primitiva com o natural, resta-nos pensar sobre a mudança de orientação estética que se teve na literatura brasileira, principalmente a partir da década de 1930, quando os pobres, sistematicamente, invadiram os enredos dos livros. A título de exemplificação, temos que, em vários livros de Jorge Amado, o outro é visto de maneira heróica, capaz de grandes transformações práticas na vida social. Em outros autores, regionalistas mais típicos, o outro é representado como "coitado", merecedor de toda a piedade. Graciliano Ramos, por sua vez, aprofunda a questão da representação do outro, conferindo maior 
complexidade a tal procedimento estético e colocando em debate se é realmente possível fazê-lo. Em Vidas Secas, já vislumbramos que o outro também pode se tornar ameaçador, como no capítulo "O Soldado Amarelo", no qual Fabiano reage e chega a colocar seu facão junto à cabeça do soldado, que, injustamente, o prendeu:

Tinha medo e repetia que estava em perigo, mas isto lhe pareceu tão absurdo que se pôs a rir. Medo daquilo? Nunca vira uma pessoa tremer assim. Cachorro. Ele não era dunga na cidade? não pisava os pés dos matutos, na feira? não botava gente na cadeia? Sem-vergonha, mofino. (RAMOS, 2008, p.103).

Em Grande sertão: veredas, os catrumanos representam "as misérias mil do Brasil fundo fundo", por isso não apresentam praticamente nenhuma alteração de relação com a natureza (semelhante a Fabiano e sua família), ou seja, o convívio entre homem e natureza ainda não é regido pela dominação e subjugação. (LUKÁCS, 1967, p. 315).

Essa afirmativa tem a ver com o fato de o processo de dominação da natureza estar ligado à crescente industrialização e ao progresso e ser marcado pela dupla face da segurança e do medo - conforme Jauss e Lukács. Ademais, tem relação com o fato de esse processo não ter sido colocado em prática no povoado do Pubo, que ainda subsiste por meio da agricultura familiar mais rudimentar. Assim, os catrumanos representam um estágio remoto da relação homem-natureza.

Agora, explorando mais a trajetória de Riobaldo, que no início de sua vida não é efetivamente um membro da classe dominante, percebemos no decorrer da narrativa ainda que seja nas entrelinhas - esse desejo surgindo e se concretizando aos poucos. Mesmo quando ainda é jagunço, comandado por Zé Bebelo, já dá indícios de suas intenções ocultas. Por isso, entre seu discurso e o enredo da história, existe algumas contradições, pois por conta de sua posição (principalmente depois de se tornar um chefe) tem de dominá-los, "amaestrá-los", como diz em um trecho. Curioso notar que o texto narrativo é construído de tal modo que dificulta a percepção do leitor a respeito da contradição mencionada anteriormente: 
Os quantos homens, de estranhoso aspecto, que agitavam manejos para voltarmos de donde estávamos. Por certo não sabiam quem a gente era; e pensavam que três cavaleiros menos valessem. Mas, entendendo que do caminho não desgarrávamos, começaram a ficar estramontados. Um eu vi, que dava ordens: um roceiro brabo, arrastando as calças e as esporas. Mas os outros, chusmote deles, eram só molambos de miséria, quase que não possuíam o respeito de roupas de vestir. Um, aos menos trapos: nem bem só o esporte de uma tanga esfarrapada, e, em lugar de camisa, a ver a espécie de colete, de couro de jaguacacaca. Eram uns dez a quinze. Não consegui sentido no que eles ameaçavam, e vi que estavam aperrando as armas.

Queriam cobrar portagem? Andavam arrumando alguma jerimbamba? Não convinha avançar assim por cima deles, logo, mas também dar recuada podia ser uma vergonha. Esbarramos, neles quase encostados. Íamos esperar o resto do pessoal. E eles, ali confrontes, não explicavam razão nenhuma. Só um disse:

- “Pode não... Pode não...” (ROSA, 2006, p. 386).

Como se lê nas entrelinhas, a conjunção subordinativa "logo" sugere que mais adiante o atropelo ocorrerá, porque o recuo significa vergonha, e, mais que isso, significa a derrota do homem frente à natureza ou ao homem que julgam uma espécie rebaixada do humano, mais próxima ao bicho.

Outro ponto importante nesse fragmento é a descrição dos catrumanos como escuros - "Quase que cada um era escuro de feições, curtidos muito, mas um escuro com sarro ravo, amarelos de tanto comer só polpa de buriti [...]” (ROSA, 2006, p. 384) - pois coincide com a ideia de que aquilo que é turvo, obscuro, furta à compreensão humana e por isso é ameaçador, voltando ao tema da ameaça incompreensível que representam.

O temor advindo da dominação está presente na história da humanidade, que é também a história da dominação da natureza pelo homem. Nesse sentido, interessante destacar um trecho do texto de Engels, "Sobre o papel do trabalho na transformação do macaco em homem", de 1876:

[...] não nos deixemos dominar pelo entusiasmo em face de nossas vitórias sobre a natureza. Após cada uma dessas vitórias, a natureza adota sua vingança. É verdade que as primeiras consequências dessas vitórias são as previstas por nós, mas em segundo e terceiro lugar aparecem consequências muito diversas, 

a cada passo, os fatos recordam que nosso domínio sobre a natureza não se parece em nada com o domínio de um conquistador sobre o povo conquistado, que não é o domínio de alguém situado fora da natureza, mas que nós, por nossa carne, nosso sangue e nosso cérebro, pertencemos à natureza, encontramo-nos em seu seio, e todo o nosso domínio sobre ela consiste em que, diferentemente dos demais seres, somos capazes de conhecer suas leis e aplicá-las de maneira adequada. (ENGELS, 1876, apud ANTUNES, 2004).

\section{Representação do outro: os catrumanos e seu poder de ameaça}

Nesse momento, é fundamental sublinhar que não se pretende dar aos catrumanos um poder de ameaça incomensurável, pois a ameaça que representam é posta em um campo misto de dominação e temor. Basta lembrar que aqueles que não podem se auto-representar não se contrapõem aos projetos que lhes são impostos, vão à "mansa força" (ROSA, 2006, p. 444): os urucuianos nem lembravam mais o porquê tinham acompanhado Zé Bebelo. Vejamos ipsis litteris este fragmento, por demonstrar o viés negativo da ameaça, que em alguns momentos pode ser neutralizada:

- Não vê, Chefe, praz vosso respeito: as coisas demudaram... Que viemos com siu Zé Bebel' ... Vai, a gente gastou o entendido..." - ele disse.

-“O que Zé Bebelo falou, quando chamou vocês?”

- "A foi. Quando chamou, senhor sim..."

- "Ele prometeu vantagens?"

-"Não se diz... Chamou. Falou misturado... A gente viemos."

-"E o que é que falou?"

-“Agora, a gente não sabe mais. Falou muito razoável... Falou muito razoável... Agora, com perdão vosso, a gente esquecemos, a gente gastou o entendido... Mas muito razoável falou..." (ROSA, 2006, p. 499).

Nesse trecho, também é patente certa crítica ao discurso lógico racional, que foi utilizado por Zé Bebelo para conseguir convencer os catrumanos a segui-lo. Esse 
discurso apresenta-se, em certa medida, falacioso e demagógico; os urucuianos voltam para o mesmo lugar e estado em que se encontravam, não levam nem mesmo as "vantagens" prometidas.

Sendo assim, de início, os catrumanos ensejam medo, temor e ameaça, mas são massacrados pela dominação. São aparentemente livres e parecem viver em um outro tempo, mas a terra onde plantam sua subsistência não é deles, tem um dono que permite a estadia - não se sabe até quando. Como diz Walnice (1972, p. 41), a plebe rural é "livre, e por isso mesmo dependente." Entretanto, diferentemente dos demais jagunços, guarda-costas e sicários, ainda resta um resíduo peculiar de poder ameaçador, porque eles representam também a ameaça daquilo que não foi de todo dominado, da natureza reprimida que pode voltar de modo catastrófico, destruindo tudo e todos.

\section{Referências}

BASTOS, Hermenegildo. "As cousas têm aspectos mansos": uma antologia de ameaça da poesia de Manuel Bandeira. 2009 (inédito)

BOLLE, Willi. Grande sertão.br: o romance de formação do Brasil. São Paulo: Duas cidades/Ed. 34, 2004.

CANDIDO, Antonio. “A literatura e a formação do homem”. In: Textos de Intervenção. São Paulo: Duas Cidades; Ed. 34, 2002.

GALVÃO, Walnice Nogueira. As formas do falso: um estudo sobre a ambigüidade em Grande sertão: veredas. São Paulo: Perspectiva, 1972.

JAUSS, Hans Robert. "El arte como anti-naturaleza. A propósito del cambio de orientación estética después de 1789”. In: VILLANUEVA, Darío (Compilador). Avances en Teoría de la Literatura (Estética de la Recepción, Pragmática, Teoría Empírica y Teoría de los Polisistemas). Universidade de Santiago de Compostela, 1994.

LUKÁCS, Georg. Estetica. La peculiaridad de lo estético. Tradución de Manuel Sacristán. México: Ediciones Grijalbo, 1967.

ROSA, João Guimarães. Grande sertão: veredas. Rio de Janeiro: Nova Fronteira, 2006. 